\title{
The Effectiveness of WhatsApp Mobile Learning Activities Guided by Activity Theory on Students' Knowledge Management
}

\author{
Chokri Barhoumi \\ Taibah University, Saudi Arabia
}

\begin{abstract}
This research paper explores the effectiveness of using mobile technologies to support a blended learning course titled Scientific Research Methods in Information Science. Specifically, it discusses the effects of WhatsApp mobile learning activities guided by activity theory on students' knowledge Management (KM). During the 2014 academic year, the researcher adopted an experimental approach-based comparison between an experimental group (34 students) and a control group (34 students). The learning process of the experimental group was based on continuity between 2 hours of in-class learning and 1 hour of learning activities that were mediated by WhatsApp instant messaging each week. The control group's experience was $100 \%$ in-class with no app mediation. The researcher used the t-test to compare the means of the control and experimental groups in the test and the students' attitudes at 0.05 alpha levels. This research paper is useful for exploring the effectiveness of mobile technologies in supporting blended learning courses.
\end{abstract}

Keywords: WhatsApp; Mobile teaching; Mobile learning; Mobile tools; Activity theory

\section{Introduction}

Today, educational mobile technology is frequently used in online instruction in universities worldwide (Jimoyiannis, Tsiotakis, Roussinos, \& Siorenta, 2013). It offers students increased choices and opportunities in the context of online instruction. Online courses that incorporate mobile technologies are becoming a more frequent component in universities, and the number of web-based mobile courses has increased (Inan, Flores, \& Grant, 2010). The information and communication technologies shared between online students through social interactions on mobile tools promote opportunities for online cooperation and collaboration (Barhoumi \& Rossi, 2013). Mobile educational technologies provide online learners with opportunities to communicate and share knowledge (Nelson, Christopher, \& Mims, 2009).

Educational mobile tools have emerged and show great potential to help students construct and share information and knowledge for learning through computers or mobile devices (Pence, 2007).

Online instructors and tutors are using mobile technologies in universities around the world. In this context, the key question to answer is thus: how do we use mobile technologies such as WhatsApp in online communities? Is it better to use mobile technology to achieve cooperative and collaborative activities in a blended course? In a study by Preston and colleagues (2010), nearly $70 \%$ of the students stated that they learn equally well from online lectures as in-class 
lectures. Additionally, nontraditional students need an effective blended online learning strategy to pursue blended courses. For these reasons, the present study is conducted with nontraditional students to explore the effectiveness of the blended scenario in a course using the WhatsApp mobile application compared to $100 \%$ in-class learning. The study measures the effectiveness of the blended mode in terms of enhancing students' cognitive and attitudinal levels in the context of a course entitled Scientific Research Methods in Information Science.

The overall scope and aims of the study are very interesting, particularly considering the focus on using mobile technologies, to which great potential for supporting blended learning scenarios has been attributed. The principal aims of the article are achieved through a comparative study between the face-to-face course and the blended online course-based continuity between face-to-face learning 2 hours weekly and the inclusion of WhatsApp mobile learning activities for 1 hour every week.

\section{Theoretical Framework}

In the present study, activity theory guides the data analysis and interpretation of the study to explore the factors that influence students' participation in online discussions through mobile technologies (WhatsApp).

\section{WhatsApp Instant Messaging}

The story of WhatsApp is an archetypical success story. The app was created by Brian Anton and Jan Koom, both Yahoo employees. Supported by an 8 million dollar investment by Major Sequoia, one of Silicon Valley's most fashionable investors' holding companies, the pair launched WhatsApp in 2009 and have been very successful.

WhatsApp (from the English phrase "What's up?", meaning "What's new?") is an instant messaging application for smartphones. It allows users to exchange images, videos, and audio or written messages using their Internet connection. WhatsApp has positioned itself as a superior alternative to SMS messaging, which can be very expensive when used in foreign countries due to roaming charges; WhatsApp, in contrast, relies on the active Wi-Fi network.

Today, WhatsApp, which was acquired by Google for 1 billion dollars in April 2013, claims 400 million active monthly users. The acquisition also finally contradicted the principle of WhatsApp? by replace SMS messages with small messages within an eponym application. These messages are OTT messages, or over-the-top tell; these are multimedia messages transmitted over the Internet, non-stop to the telephone operator. Although critics have argued that WhatsApp's success derives from teenagers "sexting,", ultimately, the application took off because it was able to exploit users' desires to release themselves from their cell phone plans.

In spite of strong competition (e.g., iMessage, LINE, BBand Viber), WhatsApp remains wellanchored as a market leader in messaging applications.

The general benefits of using WhatsApp instant messaging in the blended mobile lecture are as follows: 
- WhatsApp instant messaging facilitates online collaboration and cooperation between online students connected from school or home in a blended mobile lecture.

- WhatsApp is a free application that is easy to use.

- Groups connected to WhatsApp instant massaging can share learning objects easily through comments, texting and messaging. Discussions are related to the course content taught $100 \%$ in-class.

- WhatsApp provides students with the ability to create a class publication and thereby publish their work in the group.

- Information and knowledge are easily constructed and shared through WhatsApp instant messaging.

\section{Learning Communities and Activity Theory}

In the field of online teaching and learning, a community is a group of learners who cooperate and collaborate to participate in course activities (Cross, 1998). The principal objective of this community is to advance the construction and sharing of knowledge between groups through collaborative learning activities (Bielaczyc \& Collins, 1999). Individuals who are engaged in a working group believe that their needs can be satisfied through working cooperatively and collaboratively as a community (Rovai, 2002).

Activity theory is a framework that researchers use to design and analyze interactions between members of a group and discover factors influencing their participation in online discussion. Activity theory helped the researcher find factors that influence students' participation in online discussion. Researchers frequently use activity theory to analyze human-computer interactions (Nardi, 1996). Researchers use activity theory as a conceptual framework in the field of computer and mobile technologies for describing and analyzing the structure, development and context of learning activities mediated by computers, mobile technologies, and so on. Activity theory is also used to describe and analyze the factors that influence user participation in online discussions mediated by computers or other devices. Activity theory is a suitable framework through which to design, understand and improve learning through online learning communities. Activity theory can be used to design and understand online learning communities and to evaluate human computer interaction $(\mathrm{HCl})$ activities, Web 2.0 learning communities, mobile learning communities, and many other $\mathrm{HCl}$-based applications.

Engeström (1987) developed an extension of the activity theory model that adds the component of community sharing of the same object. In this suggested model of activity theory, Engestrom added rules that mediate the learning community and the subject and create a division of labor between the community and the object.

Essentially, activity theory aims to describe, analyze and understand the mental capabilities of a single individual. The theory rejects the isolation process applied to individuals, however, such as in the case of individual learning, and considers this isolation to be an insufficient unit of analysis. The theory seeks to analyze the cultural and technical aspects of human action (Bertelsen \& Bodker, 2003). 
Activity theory is based on six related principals:

- The first principal is the orientedness of the object. The objective of the activity system has social and cultural properties in the system, such as collaborative or cooperative learning in an online course.

- Subjects are actors engaged in activities. This is considered the individual level of activity theory; students are contextual subjects engaged in collaborative learning.

- Community or externalization is considered a social context of the system and a community level of activity theory; all actors are involved in the activity system (e.g., a group of students engaged in learning based on social interaction for constructing and sharing of knowledge is an example of a learning community).

- Tools are considered a technological level of activity theory. In the system, communication between communities is mediated by tools that transmit social knowledge. It includes the artifacts used by actors in the system. Tools influence actor-structure interactions and are influenced by culture.

- The division of labor is a considered a hierarchical structure of activity or the division of activities among actors in the system.

- Rules are the conventions and guidelines regulating activities in the system, such as rules of discussion between students in collaborative learning.

Figure 1 shows three levels of activity theory: The technological level, the individual level, and the community level.

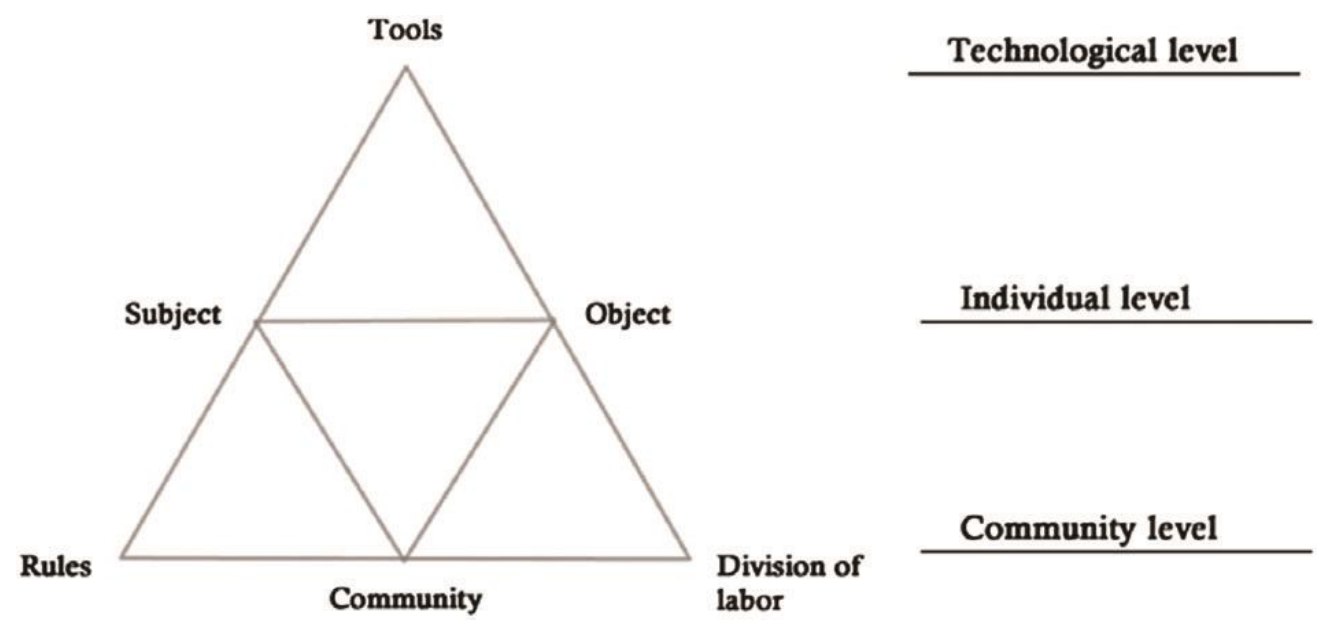

Figure 1. Three Levels of Factors that Influence Online Participation

Hewitt (2004) used activity theory to evaluate learning communities in online learning environments and to explore the factors that influence students' participation in online communities. The ease of use of the technology exploited in online learning and its usefulness are both pertinent factors that influence students' positive attitudes toward the adoption of online learning communities to construct and share knowledge.

In their research related to learning communities, Strijbos and Fischer (2007) noted that collaborative learning strategies are very useful to construct and share knowledge among 
students in collaborative and cooperative online courses in the presence of an instructor or tutor. The collaborative and cooperative learning activities achieved by students in the activity system help researchers find the cognitive outcomes of a learning activity and the processes of knowledge creation and sharing during the learning process. Activity theory stimulates professionals to renew knowledge (Tillema \& Orland-Barak, 2006).

Mercier and Higgins (2013) examined the adoption of online cooperative and collaborative learning strategies in online communities to support mathematics learning activities and found that a number of factors influencing students' participation in cooperative and collaborative communities. Students are motivated and positively oriented to participate in online communities to share knowledge related to mathematics courses.

Further, we cannot forget the principal role of the instructor in online learning activities. In this context, a recent study by Lu and Churchill (2014) stated that the teacher plays a principal role in guiding students in online lectures. This study showed that the social interaction that helps students construct and share knowledge is achieved through the pertinent role of the instructor; a decrease in the frequency of interactive messages in online communities is triggered when the online tutor or teacher is not present with the group in the online community.

Other research in the field of mobile learning has found that online learners are using mobile educational technologies and are integrating it in online learning through learning communities and that the usefulness and ease of use of the mobile technology are the principal factors influencing students' participation and adoption of online interaction (Litchfield et al, 2007). The social presence of students in online communities is a pertinent factor that influences student's participation in online communities (Cheung et al, 2008)

In an article published in Contemporary Educational Technology, Tennyson (2010) noted that in the 1990s, the integration of the media artifact by the tutor or teacher in an e-learning system was the technological factor that improved online social interaction among group members in learning communities. Social online interaction in online learning communities and its analysis became an important domain of research (Tennyson, 2010).

Baran (2010) recommended the integration of auditory and visual representations of knowledge through calculators and audiovisual media, which is considered an effective tool for solving online students' learning difficulties. These technologies may have positive results on teaching and learning.

A study conducted by Yu, Tian, Vogel, and Kwok (2010) reported that online discussions between students through social learning communities networked through an artifact, such as mobile learning communities, clearly improved students' social connections, improved their self-esteem and boosted their learning performance.

Preston and his colleagues (2010) found that nearly $70 \%$ of students state that they learn just as well in online learning communities such as WhatsApp groups, Facebook communities, Twitter chats and Google+ communities, as they do in lectures that are held in the classroom in the presence of other students. 


\section{Research Hypotheses of the Study}

The present experimental study aims to found the effectiveness of mobile technologies (WhatApp) in the achievement of learning activities compared to learning $100 \%$ in-class with no app mediation. The same course: Scientific Research Methods in Information Science was taught with the control and experimental groups.

The hypotheses guiding the present study are:

Hypothesis 1: There is a statistically significant difference between the control group and the experimental group at the 0.05 alpha level regarding the achievement test scores of students.

Hypothesis 2: There is a statistically significant difference between the control group and the experimental group at the 0.05 alpha level regarding the attitudes of students after the experimental period.

\section{Method}

The present study used an experimental research approach based on identifying the impact of the use of the blended learning process combining in-class activities and WhatsApp activities compared to the learning process that occurred entirely in the classroom.

\section{Population and Sample}

During the 2014 academic year, researchers completed a study of the blended learning process-based continuity between in-class learning and WhatsApp mobile technology to achieve learning activities compared to in-class learning only. The study sample was composed of two groups. The first group was an experimental group and contained 34 students. With this first group, the researcher applied the learning process-based continuity between face-to-face learning and WhatsApp instant messaging to achieve learning activities and discussions. The second group was a control group containing 34 students, where learning took place entirely in the classroom. The use of WhatsApp instant messaging in learning activities and discussions was new to students.

\section{The Equivalence of the Groups}

For the experiment with the learning process incorporating WhatsApp mobile learning activities to share knowledge in the course titled Scientific Research Methods in Information Science, the researchers first divided the sample into a control group and an experimental group. The two groups showed a good level of performance in using educational technologies. The researcher used an achievement test of to measure students' knowledge of general culture and the general use of instructional technology that contained no questions related to the experimented courses. The researcher divided the sample into two groups based on the results (excellent, very good, good, average, poor) (see Table 1). 
Table 1. Results of the Pres-Test Completed before the Experiment

\begin{tabular}{|c|c|c|c|c|c|}
\hline \multicolumn{6}{|c|}{ Achievement test before the experimentation } \\
\hline & & Frequency & Percent & Valid Percent & Cumulative Percent \\
\hline \multirow[t]{6}{*}{ Scales } & Excellent & 16 & 23.5 & 23.5 & 23.5 \\
\hline & Very good & 22 & 32.4 & 32.4 & 55.9 \\
\hline & Good & 10 & 14.7 & 14.7 & 70.6 \\
\hline & Average & 14 & 20.6 & 20.6 & 91.2 \\
\hline & Poor & 6 & 8.8 & 8.8 & 100.0 \\
\hline & Total & 68 & 100.0 & 100.0 & \\
\hline
\end{tabular}

\section{Tools Used for Collecting Data}

The researcher adopted the post-achievement test and the questionnaire method to collect study data.

- The first set of study data was based on the students' scores on the post-test taken after completing the experimental course.

- The second set of study data was based on the questionnaire method. The questionnaire was constructed using content validity, as established by a group of teachers at the university level. A first questionnaire was distributed in person to the experimental group to evaluate their attitudes toward the learning resource-based blended course. The control group questionnaire measured those students' attitudes towards the course conducted in the classroom without any use of mobile technology discussions.

The two questionnaires were distributed by email to a sample of teachers to measure their content validity.

\section{Justification of Measures}

The researcher began the experiment by explaining the rules for using WhatsApp instant messaging in the blended course (e.g., do not include publications that are unrelated to the course, connect to the group at the appropriate time, be respectful). The first measures in the present study were based on scores obtained by students in the post-test.

- Students' cognitive performance was based on their scores on the post-test. This measure was used to accept or reject Hypothesis 1.

- The measurement of the students' attitudes towards the experimented learning process was based on the questionnaire method. This measure was used to accept or reject Hypothesis 2. The attitudinal data obtained after the end of the experiment is considered a good indicator to explain students' motivation in using the learning process, as well as the importance of technology used in the experiment. A five-point Likert scale (strongly agree, agree, neutral, disagree, and strongly disagree) (Likert, 1932) was used for the questionnaire distributed to the control group.

The Statistical Package for Social Sciences (SPSS) software was used to analyze the study data. 


\section{Why Use the Independent Simple t-test?}

The t-test is generally used when there are two study groups, an experimental group and a control group, or for a pre- and post-test over the same group when there are more than 30 subjects in the sample. In selecting the appropriate statistical test, the researcher must verify that the data pass all of the assumptions that are required for the test. In the present study, the data pass all assumptions that are required to use the independent simple t-test to find valid results. The ANOVA test is recommended for two or more independent groups, but the simple t-test is suggested when there are only two groups: a control group and an experimental group.

\section{The Research Process in the Learning Environment of the Control and Experimental Groups}

The blended online course of the experimental group was conducted using continuity between 2 hours per week in the classroom and 1 hour per week of WhatsApp learning activities. The WhatsApp messenger is used an hour per week to discuss content taught in-class. The control group participated in 2 hours per week of in-class learning and an additional hour of face-toface learning activities. Both groups participated in 2 hours of coursework and 1 hour of learning activities to discuss course content that was covered face-to-face in the classroom. The difference between the 2 groups is that the experimental group's learning activities were mediated by the WhatsApp tool. The group participated in the same number of course and activity hours. The experimental group was created by the administrator in the WhatsApp messenger, and experimental students were invited to participate in the mobile lecture for an hour every week. All conversations in the experimental group took place in the presence of the administrator, who was the course instructor. The students were required to respect all rules as well as the set start and end times of the mobile lecture.

Figure 2 shows the experimental devices of the experimental and control groups.

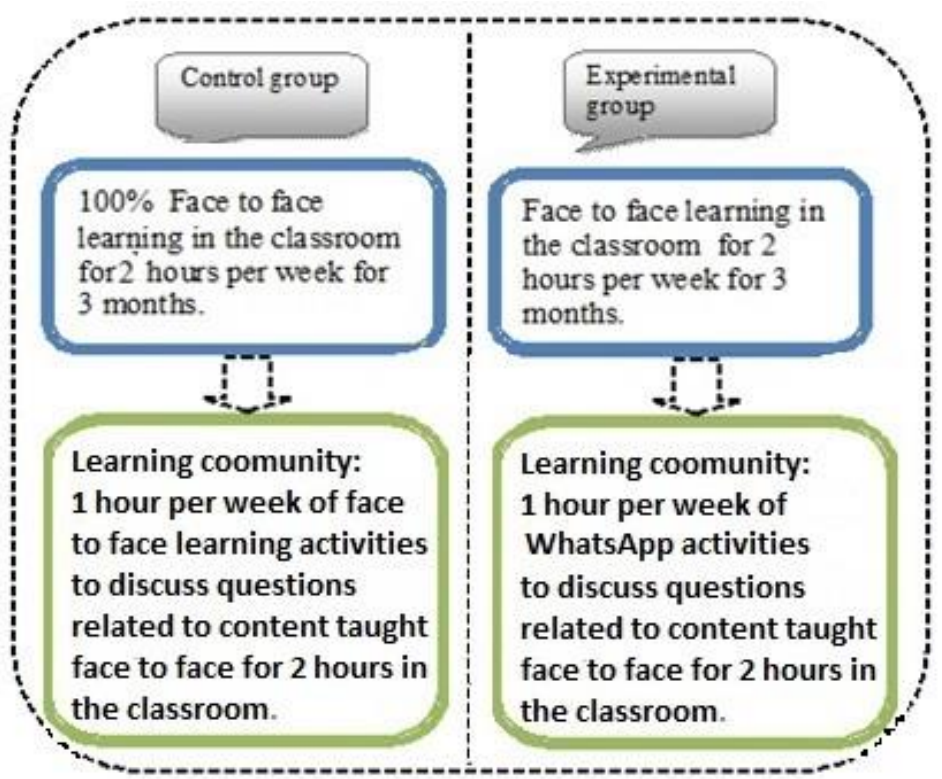

Figure 2. Experimental Devices of the Control and Experimental Groups. 


\section{Findings}

\section{Test Results}

Table 2 shows the means of the experimental and control groups and the standard deviation scores derived from statistical tests.

Table 2. Means and SD of the Control and Experimental Groups of Scores in the Test After the Experimentation

\begin{tabular}{|c|c|c|c|c|c|}
\hline \multicolumn{6}{|c|}{ Group Statistics } \\
\hline & Groups & $N$ & Mean & Std. Deviation & Std. Error Mean \\
\hline \multirow[t]{2}{*}{ Test2 } & Control group & 34 & 2.79 & 1.122 & 192 \\
\hline & Experimental Group & 34 & 3.41 & 1.158 & 199 \\
\hline
\end{tabular}

The value of the mean of the control group is 2.79, and the value of the mean of the experimental group is 3.41 (see results in Table 2). The mean of the control group (2.79) is less than the mean of the experimental group (3.41). The value of t-test obtained through the independent simple t-test can be used to explain the difference between the values of the means of the two groups in Table 3 below.

Table 3. Value of t-test obtained through independent simple t-test used for the Equality of the Mean in the Achievement Test 2

\begin{tabular}{|c|c|c|c|c|c|c|c|}
\hline & \multirow[t]{2}{*}{$t$} & \multirow[t]{2}{*}{$D f$} & \multirow[t]{2}{*}{$\begin{array}{c}\text { Mean } \\
\text { Difference }\end{array}$} & \multirow[t]{2}{*}{$\begin{array}{c}\text { Std. Error } \\
\text { Differenc } \\
e\end{array}$} & \multicolumn{2}{|c|}{$\begin{array}{c}95 \% \\
\text { Confidence } \\
\text { Interval of the } \\
\text { Difference }\end{array}$} \\
\hline & & & & & & $\begin{array}{l}\text { Low } \\
\text { er }\end{array}$ & Upper \\
\hline \multirow[t]{2}{*}{ Test2 } & $\begin{array}{l}\text { Equal variances } \\
\text { assumed }\end{array}$ & 2.234 & 66 & .618 & .277 & $\begin{array}{l}1.17 \\
0\end{array}$ & .066 \\
\hline & $\begin{array}{l}\text { Equal variances } \\
\text { not assumed }\end{array}$ & 2.234 & 65.93 & .618 & .277 & $\begin{array}{l}1.17 \\
0\end{array}$ & .066 \\
\hline
\end{tabular}

To reject or validate the first hypothesis from results of the test undertaken after the experimentation, we note the following:

Hypothesis 1: There is a statistically significant difference between the experimental group and the control group at the 0.05 alpha level regarding the achievement test scores of students after the experimental period.

The value of the t-test of the table is 2.00 , and Table 3 shows that the value of the t-test calculated for the equality of the means of the control and experimental groups is 2.234 , which is greater than the value of t-test of the table. Based on rules of independent simple t-tests, this result clearly shows the acceptance of Hypothesis 1 . There is a difference between the experimental group and the control group at the 0.05 alpha level in the students' achievement test after the experimental period. This difference is in favor of the experimental group. 
Figure 3 shows the performance of the control and experimental groups on the achievement test.

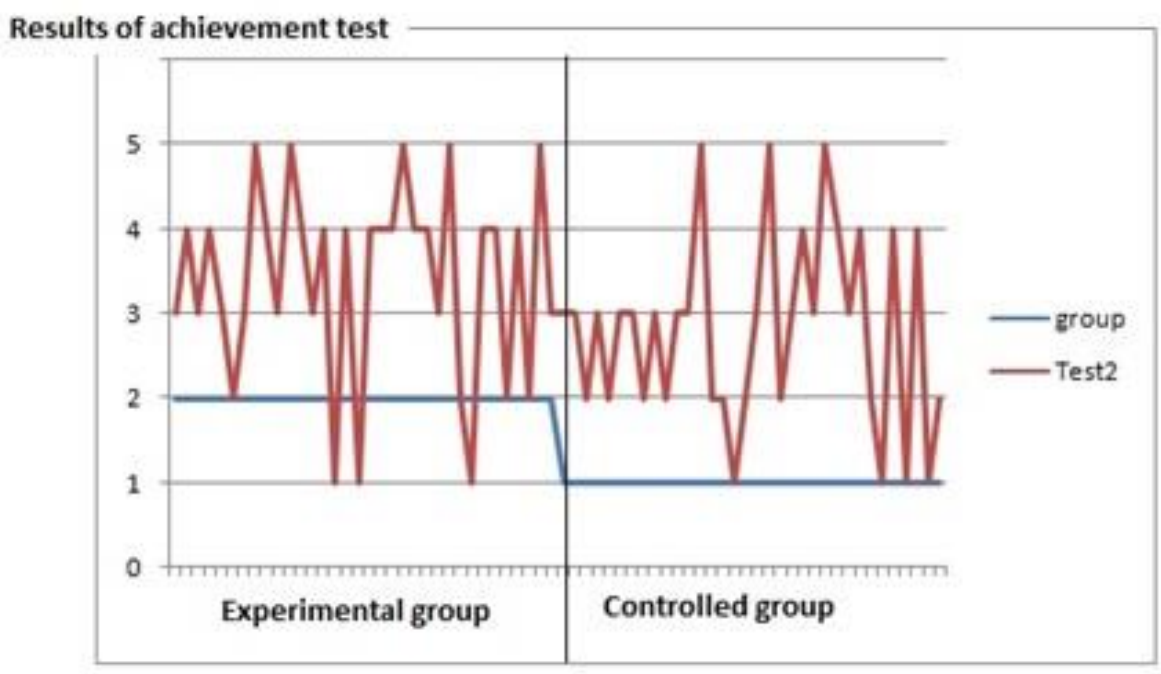

Figure 3. Results of Scores in the Test Achieved by the Experimental and Control Groups

\section{Attitudes of Two Groups towards the Experimental Learning Processes}

Table 4 shows the structure of the questionnaire designed and developed by the researcher to discover the attitudes of the experimental group toward the use of the blended learning process that combined in-class and mobile learning.

Table 4. Variables, Course, Items and Sample of the Questionnaire of the Attitudes of the Experimental Group in the Course: Scientific Research Methods in Information Science

\begin{tabular}{|l|l|}
\hline \multirow{4}{*}{ Items } & The learning is easy. \\
\cline { 2 - 2 } & Problem solving is favored. \\
\cline { 2 - 2 } & The cognitive legibility is provided for us. \\
\cline { 2 - 2 } & The knowledge is clearly constructed and shared. \\
\cline { 2 - 2 } & The research of information is favored. \\
\cline { 2 - 2 } & There is a sufficiency of the time to finish tests. \\
\hline Course & Scientific Research Methods in Information Science \\
\hline The learning process & blended learning process (70\% In presence+ $30 \%$ WhatsApp discussions) \\
\hline Items & I agree strongly, I agree, Neutral , I disagree, I disagree strongly \\
\hline$N$ & 34 \\
\hline
\end{tabular}

Table 5 describes the questionnaire distributed to the students in the control group to explore their attitudes toward the use of the learning process based $100 \%$ face to face learning. 
Table 5. Structure of the questionnaire of the attitudes of the control group in the course: Scientific Research Methods in Information Science

\begin{tabular}{|l|l|}
\hline \multirow{4}{*}{ Items } & The learning is easy. \\
\cline { 2 - 2 } & The problem solving is favored. \\
\cline { 2 - 2 } & The cognitive legibility is provided for us. \\
\cline { 2 - 2 } & The learning process used in the course favors the sharing of knowledge. \\
\cline { 2 - 2 } & The learning process used in the course favors the research of \\
\cline { 2 - 2 } & The time for the achievement of the learning activities in the course is \\
\hline The course & Scientific Research Methods in Information Science \\
\hline The learning process & $100 \%$ in presence (70\% course + 30\% discussions in class). \\
\hline Items & I agree strongly, I agree, Neutral, I disagree, I disagree strongly \\
\hline$N$ & 34 \\
\hline
\end{tabular}

Table 6 describes the means of the attitudes of the experimental and control groups.

Table 6. Means of Group Statistics

\begin{tabular}{|l|l|c|c|c|c|}
\hline & Group & $N$ & Mean & Std. Deviation & Std. Error Mean \\
\hline \multirow{2}{*}{ Attitude } & Control Group & 34 & 18.15 & 3.839 & .658 \\
\cline { 2 - 6 } & Experimental Group & 34 & 21.62 & 3.798 & .651 \\
\hline
\end{tabular}

The results regarding students' attitudes towards blended and traditional learning are shown in Table 6. The results show that the mean of the control group is 18.15 and that the mean of the experimental group is 21.62. The mean of the attitudes of the experimental group is higher than that of the control group, and the difference between the two means is clear from Table 6. To interpret the difference between the means, the researcher used the value of the t-test described in Table 7 below.

Table 7. t-test for the Equality of the Mean in the Attitudes of Students

\begin{tabular}{|c|l|c|c|c|c|c|c|}
\hline \multicolumn{2}{|c|}{} & $t$ & Df & $\begin{array}{c}\text { Mean } \\
\text { Difference }\end{array}$ & $\begin{array}{c}\text { Std. } \\
\text { error } \\
\text { Difference }\end{array}$ & \multicolumn{2}{|c|}{$\begin{array}{c}\text { 95\% Confidence } \\
\text { Interval of the } \\
\text { Difference }\end{array}$} \\
\cline { 4 - 7 } Attitude & $\begin{array}{l}\text { Equal } \\
\text { variances } \\
\text { assumed }\end{array}$ & 3.748 & 66 & 3.471 & .926 & 5.320 & 1.622 \\
\cline { 2 - 8 } & $\begin{array}{l}\text { Equal } \\
\text { variances not } \\
\text { assumed }\end{array}$ & 3.748 & 65.993 & 3.471 & .926 & 5.320 & 1.622 \\
\hline
\end{tabular}

The value of $t$ in the t-test is used to reject or validate the second hypothesis: There is a statistically significant difference between the experimental group and the control group at the 0.05 alpha level regarding students' attitudes after the experimental period.

Table 7 shows that the value of t-test calculated for the equality of the mean is (3.748), which is higher than the value of t-test of the table (2.00). This result shows that Hypothesis 2 is 
accepted and that there is a difference between the experimental group and the control group at the 0.05 alpha level in the attitudes variable. This difference is in favor of the experimental group; the attitudes of students in the experimental group towards using the blended course (70\% face-to-face course work $+30 \%$ WhatsApp discussions) are more positive and oriented toward the use of the blended learning process compared with the attitudes of the students in the control group towards in-class learning ( $70 \%$ face-to-face coursework $+30 \%$ face-to-face discussion).

Figure 4 shows the attitudes of students of the experimental and control groups based on the questionnaire method.

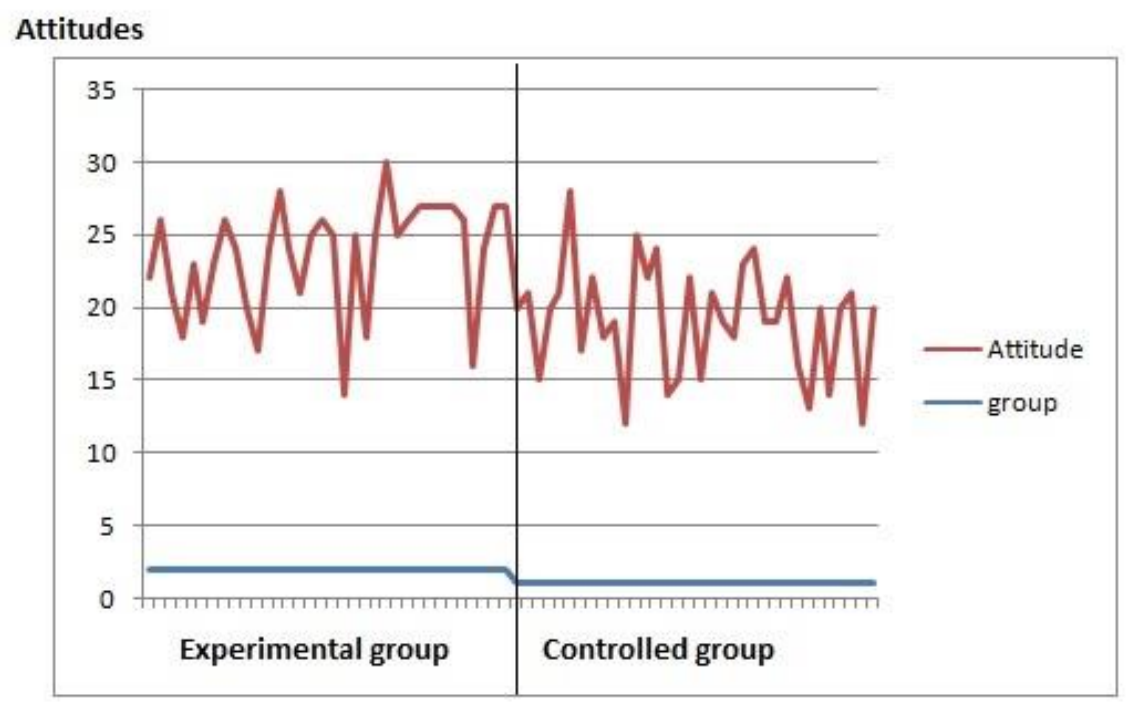

Figure 4. Results of the Attitude of the Experimental and Control Group

\section{Discussion and Implications}

The results of the present study clearly show the positive effect of the blended course $(70 \%$ face-to-face coursework $+30 \%$ of WhatsApp discussions) first on the good test results achieved after the experimentation and then on the positive attitudes of students in the experimental group compared with the students in the control group.

The researcher collected study data using the results of the achievement test and a questionnaire that explored students' attitudes towards the experimental learning process. First, the test results achieved after course completion show the cognitive performance of the students in the experimental sample compared with the control group. Second, the attitudinal data collected through the questionnaire method shows that the experimental group is more oriented and motivated to use the blended course compared with the control group, whose activities took place entirely in the classroom. The benefits of the blended course for the students in the experimental group are clear from the results of the study. The attitudes of students toward the use of WhatsApp mobile learning activities show that the learning process facilitates learning, helps students find solutions to learning difficulties and easily construct and share knowledge, and supports research into useful information for learning for a majority of students in experimental sample, compared with the control group. The learning process 
integrating WhatsApp mobile learning activities is more effective for learning and teaching than the entirely in-class learning process. Teachers using online learning methods have noted the creative use of Internet technology based on mobile learning activities and its facilitation of knowledge sharing among online students. Based on the results of the present research, WhatsApp mobile learning activities can be powerful and effective tools for students.

In the domain of habits and usability, we note that WhatsApp instant messaging is an easy to use interface for students, many of whom are familiar with its use from everyday life.

The study shows that a majority of respondents felt that social networking tools based on WhatsApp mobile learning activities can help with learning and knowledge sharing and the acquisition, dissemination, and analysis of information and knowledge.

Today, the use of WhatsApp instant messaging to improve social interaction and knowledge sharing using smartphones is increasing. Students in the experimental sample used WhatsApp frequently in their daily lives and therefore found the technology easy to use. WhatsApp instant messaging allows students to receive messages instantly. It is an interactive tool that facilitates the rapid exchange of ideas.

The students in the sample have different perceptions of the online course with or without WhatsApp instant messaging. Students in the experimental group were more encouraged and motivated to use WhatsApp instant messaging in social interactions to discuss the classroom lectures. Some factors influence the students' motivation in interacting with their peers online in course discussions. Activity theory is a suitable framework through which to examine the factors that influence students to participate in online discussion. These factors are examined at the technological, individual and community levels. The technological level is concerned with habits and usability. The individual level concerns the affordances of the tool as perceived by the students. The social presence, sense of community, community rules and rules operate on the community level. In the next section on theoretical implications, the researcher concentrates on the factors that influence students' participation in and motivation to use the WhatsApp instant messaging tool to clearly explain the difference in the achievement and attitudinal results in favor of the experimental group.

\section{Technological Level: Usability and Habits}

The use of the WhatsApp messenger to facilitate knowledge sharing in education has increased. First, students' habits and past experiences using WhatsApp and the app's perceived ease of use shapes their attitudes toward this technology. From the findings, it is clear that the experimental students' attitudes are positive and oriented toward the learning process integrating WhatsApp learning activities.

WhatsApp learning activities, which provide an easy-to-use interface coupled with a news feed feature, allow students to be quickly informed of updates within the community and respond in a timely manner. In the study by Preston and his colleagues (2010), nearly $70 \%$ of the students stated that they could learn just as well from online lectures as face-to-face lectures. In this respect, the findings of the present study confirm those of previous research projects that underscore the importance of a user-friendly Web-based platform (e.g., Cheung et al., 2008). 


\section{Individual Level: Perceptions}

Students held different beliefs regarding the affordances of the two learning processes (that is, the object that can be achieved by using the tools). The in-class learning process is a formal academic process method of learning that is used mostly to disseminate information rather than to enhance interaction. The students in the experimental group acknowledged the learning process that integrated WhatsApp mobile learning activities as a valuable process for sharing knowledge to improve learning, exchange experiences and ideas, discuss various academic and social issues and seek help and support during their learning activities. It appeared to be natural for them to create posts, share information, and conduct online discussions using the WhatsApp messenger.

From a technical perspective, Berners-Lee (2006) may have been correct that the affordances of online content creation and communication are not unique to mobile tools. The real difference between Web 1.0 and mobile technologies may involve the mentality rather than the technical capabilities.

\section{Community Level: Social Presence, Roles, and Rules}

Studies examining the impact of the social presence of teachers and students in online communities consider the former to be a principal factor influencing students' motivation for social interaction and collaboration in online teaching and learning. The presence of the teacher in the learning process is very helpful for students to construct and share knowledge. A recent study by Lu and Churchill (2014) published in the Australian Journal of Educational Technology showed that the social interaction in online learning was teacher-centered; the teacher played a central role in collaborative learning. The density of social interaction decreased remarkably when the teacher was excluded. WhatsApp mobile learning activities were initiated and run by the online instructor, and the rules for online participation and discussion were negotiated among the members of the community. The learning process of the control group designed without WhatsApp mobile learning activities was more academic and formal, and the instructor monitored the students. In this learning process, there was no sense of community and social interaction in the construction and sharing of knowledge. Students in the experimental group considered WhatsApp mobile learning activities to be an interactive space that enhanced the sense of community through sharing knowledge. The students' attitudes toward the use of the e-learning process based on WhatsApp mobile learning activities and other learning processes that were designed and developed without using WhatsApp messenger played a vital part in shaping their online activities and their roles in the online community.

Strijbos and Fischer (2007) argued that universities around the world must work to integrate cooperative and collaborative learning in the educational system to benefit the cognitive and social outcomes of learning communities and help students construct and share knowledge through online groups, especially given the low cost of these technologies.

According to Rovai (2002), students today need cooperative and collaborative learning activities to construct and share knowledge. Students are satisfied by online courses that integrate learning communities and have positive attitudes towards such courses. The increase in the use of mobile devices in the university environment helps students easily cooperate and collaborate and improves their communication. 
In their research related to social interactions in online learning communities using mobile devices Cheung et al. (2008) found that social presence is a principal factor influencing students' motivation to engage in social interactions for constructing and sharing knowledge. The study confirmed the importance of an online social presence in helping learners become more engaged.

Instant messaging for academic purposes using WhatsApp provides students with opportunities to interact and construct and share knowledge (Chan, 2005). Instant messaging is considered an effective tool for learning and teaching through social interactions (Gillingham \& Topper, 1999).

The findings of the present study based on activity theory support the value of implementing collaborative and whole-class learning activities, designed to provide opportunities for students to share experiences and knowledge through discussion and comments on the WhatsApp messenger. Tillema and Orland-Barak (2006) indicated in their research that collaborative teamwork is increasingly being used to stimulate professionals to develop and renew their knowledge and keep abreast of new developments in their fields.

\section{Limitations}

The limitations of present study are as follows:

- The number of items of the questionnaire was limited to 6 .

- The present experimental study took place in the context of a single course, "Scientific Research Methods in Information Science," and it should be replicated in other online disciplines.

\section{Conclusions and Recommendations}

There is a general growing research interest in collaborative learning activities and the sense of learning communities in the educational context, and cognitive, motivational, and affective benefits of collaboration have been found. The aspects studied include students' productive engagement in peer interactions, features of group dialog and discourse leading to high quality learning, the shared regulation of joint activities, and the relationship between online groupwork and social and emotional aspects of peer-interaction.

Based on the results of the study, the researchers advise teachers and actors in mobile teaching and learning to use WhatsApp mobile application only to pursue learning activities in a blended course integrating both face to face learning and mobile learning. The results of the study show that WhatsApp is a good tool for mobile learning when it is used in a blended course strategy. In a blended mobile lecture, mobile applications such as WhatsApp are preferred over face-to-face, in-class discussion in regard to completing course activities.

In a blended mobile lecture, anything posted by students or teachers will be instantly accessible for online students working from school or home. The results of the present research show that WhatsApp mobile learning activities carry benefits for students' achievement and attitudes towards mobile learning and teaching. 
The benefits of the WhatsApp tool in a blended mobile lecture environment are as follows:

- The tool facilitates online discussions and collaboration from school or home in a blended mobile lecture.

- In a blended mobile lecture, online students can easily discuss different topics related to the course taught face-to-face in the classroom.

- The tool facilitates of the creation of a class publication that students can edit and publish by engaging in collaborative and cooperative online activities related to the course taught in the classroom.

- It encourages students to insert text and messages to easily share information and knowledge related to the course taught face to face in a blended mobile lecture.

- WhatsApp learning technologies can help students integrate videos, podcasts, messages, texts, images and audio files in the blended mobile learning process.

The present study explored the effectiveness of the blended learning process using WhatsApp learning activities to discuss questions posed by the online instructor and related to classroom content. The results of the present study confirms the results of the study by Williams, Birch, \& Hancock (2012) demonstrating that online lectures are more effective when combined with attending face-to-face lectures. Future research could fruitfully compare the $100 \%$ online lecture format to blended lectures based on continuity between face-to-face lectures and online lectures.

\section{References}

Barhoumi, C. \& Rossi, PG. (2013). The effectiveness of the instruction oriented hypertext systems compared to direct instruction in e-learning environment. Contemporary Educational Technology, 4(4), 281-308.

Baran, B. (2010). Experiences from the process of designing lessons with interactive whiteboard: ASSURE as a road map. Contemporary Educational Technology, 1(4), 367380 .

Bertelsen, O. W. and S. Bodker. (2003). Activity theory. In J. M. Carroll (Ed.), HCl models, theories, and frameworks: Toward a multidisciplinary science (pp.291-324). San Francisco, CA: Morgan Kaufmann.

Bielaczyc, K. \& Collins, A. (1999). Learning communities in classrooms: a reconceptualization of educational practice. In C. M. Reigeluth (Ed.). Instructional design theories and models, 2, 269-291. Mahwah, NJ: Lawrence Erlbaum Associates.

Chan, L. (2005). WebCT revolutionized e-learning. UBC Reports, 51(7). Retrieved on 10 July 2015 from http://news.ubc.ca/ubcreports/2005/05jul07/webct.html

Cheung, W. S., Hew, K. F., \& Ng, S. L. (2008). Toward an understanding of why students contribute in asynchronous online discussions. Journal of Educational Computing Research, 38(1), 29-50.

Cross, K. P. (1998). Why learning communities? Why now. About Campus, 3(3), 4-11. 
Engeström, Y. (1987). Learning by expanding: An activity-theoretical approach to developmental research. Helsinki, Finland: Orienta-Konsultit Oy.

Gillingham, M. G. \& Topper, A. (1999). Technology in teacher preparation: Preparing teachers for the future. Journal of Technology \& Teacher Education, 7(4), 303-321.

Hewitt, J. (2004). An exploration of community in a knowledge forum classroom: an activity system analysis. In S. A. Barab, R. Kling, \& J. H. Gray (Eds.), Designing for virtual communities in the service of learning (pp. 210-238). Cambridge: Cambridge University Press.

Inan, F. A., Flores, R., Grant, M.M. (2010). Perspectives on the design and evaluation of adaptive web based learning environments. Contemporary Educational Technology, 2010, 1(2), 148-159.

Jimoyiannis, A., Tsiotakis, P., Roussinos, D., \& Siorenta, A. (2013) Preparing teachers to integrate mobile in school practice: Toward a framework for Pedagogy 2.0. Australasian Journal of Educational Technology, 29(2), 248-26.

Laningham, S. (2006). DeveloperWorks interviews: Tim Berners-Lee. Retrieved on 30 November 2014 from www.ibm.com/developersworks/podcast/dwi/cm-int082206txt.html.

Lu, J. \& Churchill, D. (2014). Using social networking environments to support collaborative learning in a Chinese university class: Interaction pattern and influencing factors. Australasian Journal of Educational Technology, 30(4), 472-486.

Likert, R. (1932). A technique for the measurement of attitudes. Archives of Psychology, 140, 1-55.

Litchfield, A., et al. (2007). Directions for m-learning research to enhance active learning. Paper presented at ASCILITE. Singapore.

Nardi, B. (Ed.). (1996). Context and consciousness: Activity theory and human computer interaction. Cambridge, MA: MIT Press.

Nelson, J., Christopher, A., \& Mims, C. (2009). TPACK and Mobile: Transformation of teaching and learning. TechTrends: Linking Research \& Practice to Improve Learning , 53(5), 80-87.

Preston, G., Phillips, R., Gosper, M., McNeill, M., Woo, K., \& Green, D. (2010). Web-based lecture technologies: Highlighting the changing nature of teaching and learning. Australasian Journal of Educational Technology, 26(6), 717-728.

Pence, H. E. (2007). Preparing for the real Web generation. Journal of Educational Technology Systems, 35(3), 347-356.

Rovai, A. P. (2002). Development of an instrument to measure classroom community. Internet and Higher Education, 5, 197-211.

Strijbos, J. W. \& Fischer, F. (2007). Methodological challenges for collaborative learning research. Learning and Instruction, 17(4), 389-393.

Tillema, H. Orland-Barak, L. (2006). Constructing knowledge in professional conversations: The role of beliefs on knowledge and knowing. Learning and Instruction, 16, 592-608.

Williams, A., Birch, E., \& Hancock, P. (2012). The impact of online lecture recordings on student performance. Australasian Journal of Educational Technology, 28(2), 199-213. 
Yu, A. Y., Tian, S. W., Vogel, D., \& Kwok, R. C. W. (2010). Can learning be virtually boosted? An investigation of online social networking impacts. Computers \& Education, 55(4), 14941503.

Correspondence: Assistant Professor, Department of Information Sciences and Learning Resources, Faculty of Education and Human Sciences, Taibah University, Madinah Mounawwara, Saudi Arabia 